\title{
Erratum
}

\section{Behavioral Adaptation of Pan troglodytes troglodytes $^{1}$}

\author{
Kay H. Farmer, ${ }^{2}$ Hannah M. Buchanan-Smith , ${ }^{2,4}$ and Aliette Jamart ${ }^{3}$
}

Published Online August 8, 2006

\section{INTRODUCTION}

End of paragraph 4-"Release onto islands has resulted in 2 nutritionally self-sufficient populations, and 1 in Tanzania (Borner, 1985)." should read "Release onto islands has resulted in 1 nutritionally self-sufficient population in Tanzania (Borner, 1985)."

${ }^{1}$ International Journal of Primatology, DOI: 10.1007/s10764-006-9041-4.

${ }^{2}$ Scottish Primate Research Group, Department of Psychology, University of Stirling, Stirling, FK9 4LA, Scotland United Kingdom.

${ }^{3}$ Habitat Ecologique et Liberté des Primates, BP 335, Pointe-Noire, Republic of Congo.

${ }^{4}$ To whom correspondence should be addressed; e-mail: h.m.buchanan-smith@stir.ac.uk. 